\title{
Prólogo \\ Seguridad y democracia: ¿antinomia irreductible?
}

\author{
Carlos Durán Migliardi \\ CEDER, Universidad de Los Lagos, Santiago, Chile. \\ Email: carlos.duran@ulagos.cl
}

Luis Eduardo Thayer

Universidad Central, Santiago de Chile.

Email: luis.thayer@ucentral.cl

Durante el siglo XX, los desarrollismos latinoamericanos incorporaron un sentido de integración social basado en una oferta estatal de certidumbre. La legitimidad social y política del Estado estaba en gran medida amparada en un conjunto de políticas de producción de seguridad jurídica, de bienestar y de certezas en cuanto a la proyección de la vida, tanto en el ámbito laboral, ambiental como también territorial. Esta respuesta política a las incertidumbres estructurales e inherentes de la modernidad y de los modernismos, marcó el sentido y espíritu de una parte significativa de las políticas, programas y grandes pactos sociales impulsados por los Estados.

El derrumbe, por una parte, de las condiciones políticas y, por otra, de los consensos y disposiciones sociales para la producción de certidumbres, puso en el centro de la política la capacidad de adaptación, y ya no de confrontación, a los riesgos inherentes de la modernidad global. Y es que, en un estado de cosas en el que se exacerba la indeterminación y en donde los ciudadanos dejan de recibir la promesa estatal de certidumbre, la incerteza vuelve a ubicarse en el centro de la experiencia de esta nuestra modernidad tardía, aunque la respuesta es ahora de una naturaleza distinta.

La reinterpretación del riesgo, desde esta mirada adaptativa, ha implicado el desarrollo de todo un conjunto de políticas paliativas que dan la espalda a las condiciones originarias de los riesgos e incertidumbres, las que no solo se reproducen sino que, como han inventariado profusamente las ciencias sociales de fines del siglo XX y principios del XXI, tienden a extenderse- -no solo territorialmente-, integrando cada vez más rincones del planeta, alcanzando cada vez más dimensiones de la vida.

Este cambio desde la política de producción de certidumbres a una política de adaptación al riesgo ha implicado una reinterpretación de la certeza desde lo que podemos llamar el código de la seguridad pública, y a la vez una redefinición de la noción de riesgo, la que ha dejado de ser 
concebida en relación a las condiciones de su producción, trasladándose a las manifestaciones más patentes encarnadas en la figura del enemigo.

Esta nueva política tiene sin embargo un antecedente histórico que se remite a los propios fundamentos del contractualismo. Ya desde inicios del siglo XIX, el Estado moderno se erigió como la representación de la demanda de orden y seguridad, desplegando un conjunto de instrumentos de disciplina y control sobre la población, desarrollando un discurso de la seguridad y estableciendo múltiples mecanismos de corrección y/o reencauzamiento de aquellas conductas consideradas como atentatorias contra el orden social. La misma emergencia de las "ciencias sociales positivas” entroncan con esta voluntad política. De este modo, el Estado moderno logra identificar los intereses de reproducción del sistema social con el interés individual, al punto de producir un estado de cosas en el cual "el nivel de las políticas de seguridad dirigidas a los ciudadanos está orientado siempre en función de la seguridad del sistema”.

La re-emergencia de la política de la seguridad restituye de algún modo está lógica original, donde el monopolio del uso legítimo de la violencia se sublima, al punto de trascender a la institución estatal, para amparar cualquier violencia que se haga en su nombre. Las políticas de seguridad que ejemplarmente viene impulsando Europa y Estados Unidos desde fines del siglo pasado, y con intensidad desde inicios del presente, en contra de sus enemigos internos y externos, constituye la expresión paradigmática de este proceso, y el modelo que los Estados Latinoamericanos están comenzando a asimilar. La represión y persecución en contra de las expresiones culturales que tensionan los valores que han logrado cierta hegemonía; el cierre de las fronteras para restringir el acceso de migrantes estigmatizados como enemigos, narcotraficantes, enfermos portadores de plagas, terroristas, delincuentes o pervertidos destructores de la familia; el virtual cierre de espacios urbanos para garantizar la exclusión territorial de aquellos que están excluidos de los beneficios y excedentes que concentra las ciudades; el desarrollo de nuevas y sofisticadas formas de control latente como complemento de incidencia subjetiva, de las expresiones más brutales de la represión violenta en contra de sujetos denominados como disruptores del orden; la especialización mediática en la producción del miedo y los enemigos como línea editorial congruente con una política cada vez más inspirada en el estado de excepción, son algunas de las manifestaciones más evidentes y en franco crecimiento que dan cuenta de esta nueva política de la seguridad.

Polis, Revista Latinoamericana, se propuso producir un número dedicado a estos tópicos, de cara a comprender y problematizar el proceso de securitización de la política en los Estados y sociedades latinoamericanas, y reflexionar acerca de la compleja relación entre seguridad y democracia.

Los artículos que componen la sección Lente de aproximación de este número monográfico de Polis encaran, desde distintas perspectivas, esta interesante problemática. En primer lugar, el trabajo de Mercedes Cal- 
zado y Juan Pedro Gallardo nos introducen directamente al tópico de la securitización del debate público y la puesta en el centro mediático de una agenda vinculada al "control del delito", observando la forma en que dicha agenda se representó en la contienda electoral por el Gobierno de la Ciudad de Buenos Aires del año 2007. Observando de qué modo las referencias a la "seguridad pública”, el "control de la delincuencia” y la "represión al delito" se encontraban presentes en las propuestas y estrategias de campaña de todos los candidatos, los autores observan de qué modo "nos encontramos ante un declive del ideal rehabilitador" a la hora de tematizar los asuntos relativos a la seguridad.

Luego de este trabajo, el lector encontrará cuatro artículos que, desde distintas perspectivas, abordan la relación entre seguridad e inmigración, tópico de gran actualidad para nuestros tiempos de globalización y debilitamiento de las otrora fuertes fronteras estado-nacionales. El artículo de Andrés Pereira nos conduce a la instalación temprana de esta relación durante las primeras décadas del Siglo XX, en donde se despliega, para el caso argentino, "un conjunto de discursos y prácticas, configurados por el pensamiento de Estado, que producen a la inmigración como una amenaza para el orden social establecido por las élites”.

En el siguiente texto de Romina Ramos y Cristian Ovando, este debate en torno a la relación entre seguridad y migración se traslada hacia la frontera norte de Chile. Comprendiendo que los dispositivos de la seguridad no provienen exclusivamente del ámbito institucional, este trabajo se propone "identificar, a través del discurso, la percepción que tienen algunos actores transfronterizos de la región de Tarapacá sobre las formas de apropiación del espacio y mecanismos de control que se gestan desde las prácticas políticas”. Centrándose en un estudio de las representaciones de funcionarios estatales ubicados en la zona fronteriza de Tarapacá, los autores profundizan en la forma en que dichos actores viven la frontera: ¿Qué ocurre con los actores de aquel espacio que circulan e interactúan transfronterizamente?; ¿cómo opera la dialéctica entre control y apertura?; ¿de qué modo sus acciones y representaciones expresan y/o subvierten la primacía del discurso de la seguridad?

Volviendo al eje normativo instalado en el texto de Andrés Pereira, el trabajo de Fernanda Stang nos ofrece una elaborada reflexión en torno a la forma en que la legislación migratoria chilena, desde 1975, ha centralizado la preocupación por la seguridad como móvil de sus intenciones normativas. Este texto muestra de qué forma la actual normativa migratoria que rige a Chile, originada en un contexto dictatorial, se encuentra estrechamente articulada por el imperativo de la seguridad. Más allá de los relevantes cambios tanto en los objetivos como en la operatoria misma de la legislación migratoria, sostiene Stang, "lo cierto es que la persistencia del trasfondo restrictivo y persecutor de su texto sigue teniendo consecuencias que hacen urgente la modificación de este régimen legal”.

El último de los trabajos centrado en el tópico migratorio correspon- 
de a Luis Eduardo Thayer, quien dirige su reflexión hacia las condiciones sociales que explican la asociación entre seguridad y migración en las sociedades receptoras. Negando las explicaciones que reducen la producción del rechazo a los inmigrantes a factores estrictamente económicos, el autor afirma la existencia de un complejo fenómeno que, vinculando condicionantes objetivas con percepciones y expectativas de migrantes y nativos, reproduce una "dualidad entre las condiciones estructurales que incentivan los flujos migratorios y el desprecio social hacia los migrantes que alimenta la represión Estatal, (lo que) está llevando a la consolidación de la crisis definitiva de los derechos humanos como referente para la convivencia y la construcción de las democracias occidentales”.

El siguiente artículo, de autoría de Martín Tironi y Matías Valderrama, nos adentra en la traducción del fenómeno de la seguridad a la escala de los gobiernos locales. A partir de la descripción de un evento particular, consistente en la instalación de globos aerostáticos de vigilancia en dos comunas de altos ingresos de la ciudad de Santiago, los autores reflexionan en torno a la relación entre la demanda securitaria y la producción de vigilancia. Junto con exponer el debate en torno a las relaciones de continuidad y ruptura entre la vieja fórmula foucaultiana del panóptico y las invisibles técnicas propias de la deleuziana “sociedad del control”, Tironi y Valderrama reflexionan en torno al estatuto de este dispositivo físico: ¿Cuánto de invocación y continuidad se expresan en un aparato de vigilancia originariamente creado con fines militares?; ¿Qué tanto de disciplina y que grado de control expresa este aparato ubicado en los cielos de la capital de Chile? Finalmente, los autores exponen una interesante descripción de las disposiciones discursivas que, en el contexto del debate público generado por la instalación de estos globos de vigilancia, se generaron tanto para apoyar como para rechazar su uso.

El artículo de Iván Torres, por su parte, constituye una reflexión teórica acerca de lo que el autor denomina como "racionalidad securitaria de las prácticas de gobierno neoliberales”. Observando de qué modo el actual contexto epocal establece una peculiar relación entre democracia y excepción, se describen algunas de las perspectivas contemporáneas críticas de la securitización de las prácticas de control estatal.

Los dos últimos artículos de la sección dirigen su mirada hacia el actor juvenil, uno de los objetos privilegiados de los discursos y dispositivos asociados al imperativo de la seguridad. El artículo de Alejandro Tsukame, primero, expone una interesante descripción de la construcción discursiva, en distintas coyunturas del contexto chileno postdictatorial, de la imagen del joven delincuente/peligroso. Partiendo de la base de que "Los medios de comunicación constituyen una institucionalidad relevante en el proceso que incide en el carácter centralmente punitivo del sistema de justicia en general y de la justicia adolescente en particular”, el autor se centra en la forma en que éstos relevan de modo sistemático la asociación entre conducta juvenil, exceso, delito y peligro. 
El trabajo de Alfonso Valenzuela-Aguilera, cierra esta sección, ofreciendo los resultados de un estudio cuantitativo referido a la percepción de inseguridad en adolescentes habitantes en la ciudad mexicana de Cuernavaca. Observa la presencia de fuertes dosis de resiliencia que permiten a los jóvenes adolescentes convivir con un contexto territorial caracterizado por sus altas dosis de violencia, el artículo destaca la importancia de la dimensión territorial y la cultura cívica en la reconstitución de los lazos sociales amenazados por la violencia y la desprotección estatal.

Estos son los trabajos incluidos en nuestro lente de aproximación Democracia y seguridad. $\dot{\boldsymbol{d}}$ Antinomia irreductible? Como puede observar el lector, los artículos presentados exponen solo algunas de las múltiples estrategias de abordaje y perspectivas teóricas posibles de operativizar frente a un tema de amplio espectro.

El número 44 de POLIS, Revista Latinoamericana, está integrado además por la sección "Propuestas y avances de investigación” que contiene un total de once artículos y la sección "Comentarios y reseñas de libros" compuesta por cuatro textos. 